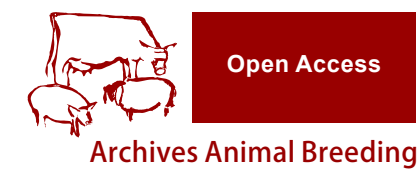

Supplement of

\title{
Genetic diversity and relationship among indigenous Turkish Karayaka sheep subpopulations
}

\section{Koray Kirikci et al.}

Correspondence to: Koray Kirikci (koray.kirikci@ahievran.edu.tr)

The copyright of individual parts of the supplement might differ from the CC BY 4.0 License. 
Table S1. Private alleles and their frequencies for loci per population.

\begin{tabular}{|c|c|c|c|c|c|}
\hline \multirow[t]{2}{*}{ Locus name } & \multirow[t]{2}{*}{ Alleles } & \multicolumn{4}{|c|}{ Populations } \\
\hline & & Samsun & Ordu & Giresun & Tokat \\
\hline \multirow[t]{10}{*}{ BM757 } & 170 & & & $0.067 *$ & \\
\hline & 174 & & & $0.133^{*}$ & \\
\hline & 178 & & 0.031 & & \\
\hline & 180 & & $0.219 *$ & & \\
\hline & 192 & & 0.031 & & \\
\hline & 194 & 0.031 & & & \\
\hline & 196 & 0.031 & & & \\
\hline & 208 & 0.031 & & & \\
\hline & 210 & 0.031 & & & \\
\hline & 214 & $0.063 *$ & & & \\
\hline \multirow[t]{5}{*}{ BM827 } & 220 & & & $0.252 *$ & \\
\hline & 238 & & & & $0.063 *$ \\
\hline & 242 & 0.031 & & & \\
\hline & 152 & & & $0.071 *$ & \\
\hline & 156 & & & $0.071 *$ & \\
\hline \multirow[t]{3}{*}{ BM6526 } & 160 & & & & 0.031 \\
\hline & 182 & 0.031 & & & \\
\hline & 186 & 0.033 & & & \\
\hline \multirow[t]{6}{*}{ BM8125 } & 104 & 0.031 & & & \\
\hline & 108 & & & 0.031 & \\
\hline & 110 & & & & 0.031 \\
\hline & 134 & & $0.071 *$ & & \\
\hline & 136 & & 0.036 & & \\
\hline & 138 & & & & 0.031 \\
\hline \multirow[t]{5}{*}{ BM1314 } & 140 & $0.077 *$ & & & \\
\hline & 146 & & & $0.273 *$ & \\
\hline & 150 & & & & $0.094 *$ \\
\hline & 162 & & & & $0.125 *$ \\
\hline & 182 & $0.077 *$ & & & \\
\hline CSSM47 & 140 & & & $0.063 *$ & \\
\hline \multirow{11}{*}{ HUJ616 } & 116 & & & $0.143^{*}$ & \\
\hline & 118 & & $0.188 *$ & & \\
\hline & 120 & & $0.094 *$ & & \\
\hline & 130 & $0.125 *$ & & & \\
\hline & 134 & & $0.063 *$ & & \\
\hline & 142 & 0.031 & & & \\
\hline & 148 & & & $0.071 *$ & \\
\hline & 150 & 0.031 & & & \\
\hline & 160 & & & & $0.063 *$ \\
\hline & 166 & & $0.063 *$ & & \\
\hline & 178 & & $0.063 *$ & & \\
\hline \multirow[t]{9}{*}{ MAF33 } & 102 & & 0.031 & & \\
\hline & 112 & & $0.063 *$ & & \\
\hline & 114 & & 0.031 & & \\
\hline & 116 & & & $0.094 *$ & \\
\hline & 130 & & $0.063 *$ & & \\
\hline & 140 & 0.333 & & & \\
\hline & 146 & 0.033 & & & \\
\hline & 164 & & 0.031 & & \\
\hline & 180 & & 0.031 & & \\
\hline \multirow[t]{3}{*}{ OarFCB304 } & 186 & & & & $0.154 *$ \\
\hline & 210 & & & & 0.039 \\
\hline & 222 & & & & 0.039 \\
\hline Total & & 16 & 16 & 11 & 10 \\
\hline
\end{tabular}

*Private alleles with frequency higher than $5 \%$. 